\title{
THE EFFECT OF ROUGHNESS ON THE RATE OF ICE ACCRETION ON A CYLINDER
}

\author{
by \\ LASSE MAKKONEN \\ Laboratory of Structural Engineering, Technical Research Centre of Finland, \\ Betonimiehenkuja 3, 02150 Espoo, Finland

\section{J. R. STALIabrass}

Low Temperature Laboratory, Division of Mechanical Engineering, National Research Council Canada, Ottawa, Ontario K1A OR6, Canada

\section{ABSTRACT}

The rate of icing in the wet growth conditions typical of ship icing and icing in freezing precipitation depends on the rate at which the heat liberated in the freezing process is transferred to the environment. A theoretical model for the heat transfer from the front half of a rough cylinder, based on boundary-layer theory, is described.

Comparisons with empirical data show that the model simulates well the overall heat transfer rate from the front half of a cylinder with distributed roughness. The theory provides improved agreement between the results of a numerical icing model and icing wind tunnel tests.

\section{INTRODUCTION}

The icing of structures at the earth's surface of ten occurs under conditions where the flux of water droplets impinging the surface is sufficiently high that all the water does not freeze and the excess water runs off from the surface. This kind of wet growth icing is a serious problem for objects such as power line cables, masts and superstructures of a ship. Under wet growth conditions the rate of icing depends on the rate at which the latent heat liberated in the freezing can be transferred to the environment, ie the icing rate on an object under wet growth conditions is determined largely by the heat transfer coefficient around the front half of the object.

When icing occurs, the resulting ice surface is of ten quite rough. Moreover, the roughness characteristics may change both in space and in time during the icing process. Increasing roughness causes an earlier transition from a laminar to a turbulent boundary-layer and increases the heat transfer rate in the turbulent part of the boundary-layer.

Attempts have been made to take the effect of roughness into account in the icing models, by using simple fits to experimental data on heat transfer from rough cylinders (Lozowski and others 1983; Makkonen 1984). However, there is clearly a need for theoretical description of the effect of roughness in the icing models.

In this paper a boundary-layer model for calculating the local heat transfer coefficient around the front half of a cylinder is described. The emphasis is to simulate the overall heat transfer from the front half of a cylinder, although detailed distribution of the local heat transfer coefficient must be modeled for this purpose. The application is mainly where icing occurs under conditions where the shape of the object remains nearly cylindrical during the icing process (transmission line cables, for example).
THE MODEL

Boundary-layer equations

The theory is described in detail by Makkonen (1985). Here, only the basic principle of the model is given. The model assumes an infinitely long cylinder of diameter $\mathrm{D}$, and considers a steady two-dimensional incompressible boundary-layer on its surface from $\theta=0^{\circ}$ (stagnation line) to $\theta=90^{\circ}$. Under these assumptions the boundary-layer equation of the forced flow reduces to:

$$
u \frac{\partial u}{\partial x}+v \frac{\partial u}{\partial y}=-\frac{1}{\rho} \frac{d p}{d x}+\frac{1}{\rho} \frac{\partial \tau_{0}}{\partial y}
$$

where $u$ and $v$ are the flow velocity components, $\rho$ is the air density, $p$ the pressure and $v$ the kinematic viscosity of air and $\tau_{0}$ is the shear stress at the wall $(y=0)$.

It is assumed that the velocity distribution outside the boundary-layer is:

$$
u_{\infty}(x)=1.58 \sin (1.233 \theta(x)) U
$$

where

$$
\theta(x)=\frac{2 x}{D}
$$

and $U$ is the free stream velocity.

Equation 2 is based on the observed pressure distributions around rough cylinders (Guven and others 1980; Nakamura and Tomonari 1982) which show little dependency on the cylinder Reynolds number and the roughness element height. Integrating (1) with respect to $y$ from $y=0$ (wall) to $y=\infty$ and taking into account the continuity equation and the Bernoulli equation, the momentum-integral Equation 4 is obtained.

$$
\frac{T_{0}(x)}{\rho}=\frac{d}{d x}\left[u_{\infty}(x) \delta_{2}(x)\right]+\delta_{1}(x) u_{\infty}(x) \frac{d u_{\infty}(x)}{d x}
$$

where $\delta_{1}$ is the displacement thickness and $\delta_{2}$ is the momentum thickness, respectively (Kays and Crawford 1980: 50).

Using the approximate solution of Equation 4 for the momentum thickness in a laminar boundary-layer, and deducing the energy-integral equation for a laminar boundary-layer by multiplying Equation 1 by $u$ and applying the same integration, it can be shown (Kays and Crawford 1980) that the local cylinder Nusselt number $\mathrm{Nu}_{4}$ on a cylinder with a diameter $\mathrm{D}$ in the laminar region is: 


$$
\mathrm{Nu}_{\mathrm{L}}=\frac{0.293 \mathrm{D} \mathrm{U}_{\infty}^{1.435}(\mathrm{x})}{v^{0.5}\left[\int_{0}^{\mathrm{x}} \mathrm{u}_{\infty}^{1.87}(\mathrm{x}) \mathrm{dx}\right]^{0.5}}
$$

The power-law for the normal velocity distribution in the turbulent boundary-layer, which follows from Prandtl's mixing length theory, results in the following equation for the shear stress $\tau_{0}$, evaluated at the wall surface (Kays and Crawford 1980):

$$
\tau_{0_{T}}(x)=0.0125 \rho u_{\infty}^{2}(x)\left[\frac{\delta_{2}(x) u_{\infty}(x)}{v}\right]^{-0.25}
$$

When Equation 6 is substituted in the momentum-integral Equation 4 the solution for the momentum thickness $\delta_{2}$ for the turbulent boundary-layer (Kays and Crawford 1980) is:

$$
\delta_{2}(x)=\frac{0.036 v^{0.2}}{u_{\infty}^{3.29}(x)}\left[\int_{0}^{x} u_{\infty}^{3.86}(x) d x\right]^{0.8}
$$

The stanton number St for a fully rough flow (Kays and Crawford 1980) is:

$$
\operatorname{St}(x)=\frac{c_{f}(x) / 2}{\operatorname{Pr}_{t}+\sqrt{c_{f}(x) / 2} \operatorname{St}_{k}^{-1}(x)}
$$

where $\mathrm{St}_{\mathbf{k}}$ is the Stanton number based on the friction veloicty, $c_{p}$ is the specific heat of air, and $\operatorname{Pr}_{t}$ is the turbulent Prandtl number which is approximately constant at 0.9 for gases (White 1974). The local friction coefficient $c_{f}$

$$
c_{f}(x)=\frac{T_{0}(x)}{\rho_{\infty}\left[u_{\infty}^{2}(x) / 2\right]}
$$

is related to the momentum thickness $\delta_{2}$ and to the equivalent sand grain roughness height $\mathrm{k}_{8}$ (Kays and Crawford 1980) by:

$$
c_{f}(x) / 2=\frac{0.168}{\left[\ln \left(846 \delta_{2}(x) / k_{s}\right)\right]^{2}}
$$

The parameter $\mathrm{St}_{\mathrm{k}}$ in Equation 8 is formulated using the roughness Reynolds number:

$$
\operatorname{Re}_{s}(x)=\frac{u_{T}(x) k_{s}}{v}
$$

and the Prandtl number $\operatorname{Pr}$ (Owen and Thomson 1963) by:

$$
\mathrm{St}_{\mathrm{k}}^{-1}(\mathrm{x})=\alpha \operatorname{Re}_{\mathrm{s}}^{0.45}(\mathrm{x}) \mathrm{Pr}^{0.8}
$$

According to Owen and Thomson (1963) $\alpha=0.52$ is a good approximation. The friction velocity $\mathrm{u}_{\tau}$ in Equation 11 is defined as:

$$
\mathrm{u}_{\tau}(\mathrm{x})=\sqrt{\frac{\tau_{0}(\mathrm{x})}{\rho}}
$$

where $\tau_{o_{T}}$ is evaluated from Equation 6. Finally, using

Equations 6-13 the Stanton number St is calculated and then the local Nusselt number for the turbulent region is obtained as:

$$
N u_{T}(x)=\frac{S t(x) u_{\infty}(x) \rho c_{p} D}{k_{a}}
$$

where $c_{p}$ is the specific heat and $k_{a}$ is the thermal conductivity of air.

\section{The calculation procedure}

The properties of air, $\rho, c_{p}, v$, and $k_{a}$, are temperature dependent, and the mean of the free-stream temperature and the surface temperature $\left(0^{\circ} \mathrm{C}\right)$ is assumed to represent the boundary-layer temperature in the model. The other input parameters for the model, in addition to the freestream temperature, are the free-stream velocity $U$, the cylinder diameter $\mathrm{D}$, the roughness element height $\mathrm{k}$ and the equivalent sand-grain roughness $\mathrm{k}_{\mathrm{s}}$.

If the roughness elements are not of uniform size, then the maximum probable height should be used as $k$. The calculation starts at the stagnation point $(\theta=x=0)$, where the velocity $u_{\infty}$ is zero. At that point the local Nusselt number $\mathrm{Nu}\left(0^{\circ}\right)$ is assumed to be equal to $\sqrt{\mathrm{Re}}$, where $\mathrm{Re}$ is the cylinder Reynolds number $(\operatorname{Re}=U D / v)$.

The calculation then proceeds by steps of $5^{\circ}$, and the momentum boundary-layer thickness and the local Nusselt number $\mathrm{Nu}_{\mathrm{L}}$ are calculated through numerical integration for each angular step taking into account the velocity distribution. At the first calculation point where the transition criterion shows turbulent flow, the value of $\mathrm{Nu}_{\mathrm{L}}$ is excluded and the point of transition $x_{t r}$ (and the transition angle $\theta_{\mathrm{tr}}$ ) is determined by simultaneous linear interpolation of both the criterion parameter $\mathrm{Re}_{\mathrm{k}}$ and its critical value.

The criterion parameter applied in the model is the local roughness Reynolds number

$$
\operatorname{Re}_{k}(x)=\frac{u(x, k) k}{v}
$$

where $\mathbf{k}$ is the height of the roughness elements.

The transition from laminar to turbulent flow occurs in the model at the angle $\theta_{\mathrm{tr}}$ at which

$$
\operatorname{Re}_{\mathbf{k}}\left(\mathrm{x}_{\mathrm{tr}}\right)=600 \exp [-0.9 \lambda(\mathrm{x})]
$$

where

$$
\lambda(x)=\frac{\delta_{1_{L}}^{2}(x)}{v} \frac{d u_{\infty}(x)}{d x}
$$

Beyond the transition point $\theta>\theta_{\mathrm{tr}}$ the calculation is based on the theory for the turbulent boundary-layer (Equation 14 for the Nusselt number).

When the calculation of the local Nusselt number is completed for all the calculation points $\theta=0-90^{\circ}$, the overall Nusselt number for the front half of the cylinder, $\mathrm{Nu}_{\mathrm{m}}$ is determined as the mean of the local values of $\mathrm{Nu}$.

\section{RESULTS AND DISCUSSION}

Three examples of model simulations of the variation in the local Nusselt number $\mathrm{Nu}$ are shown as solid lines in Figure 1. At the smallest cylinder Reynolds number, $\mathrm{Re}=$ $4.8 \times 10^{4}$, the flow is laminar at all angles and the heat transfer coefficient decreases slowly with increasing angle $\theta$. At the higher Reynolds number, $\mathrm{Re}=2.8 \times 10^{5}$, the transition from laminar to turbulent flow occurs at $\theta \approx 60^{\circ}$, and then decreases. The curve for the highest Reynolds number $\operatorname{Re}=8.8 \times 10^{5}$ in Figure 1 shows a qualitatively similar behaviour. The angle of maximum $\mathrm{Nu}$ at $\mathrm{Re}=8.8$ $x 10^{5}$ is $\approx 58^{\circ}$ which is almost the same as that for $\operatorname{Re}=$ $2.8 \times 10^{5}$. In fact, test simulations showed that the angle of maximum local heat transfer coefficient is between $55^{\circ}$ and $61^{\circ}$ at all combinations of $\mathrm{U}, \mathrm{D}, \mathrm{k}$ and $\mathrm{k}$ which are possible on ground-based structures, and which produce turbulent flow at the cylinder surface. A conclusion of this is that the "horns", typical of an ice shape under wet growth conditions on a non-rotating cylinder, tend to start forming at about $58^{\circ}$, regardless of the growth conditions and the cylinder size.

In the comparisons with Achenbach's (1977) data (Figures 1, 3 and 4), the cylinder Reynolds numbers and Nusselt numbers are based on the free-stream temperature of the experiment. The experimental points fall very close to the theoretical curve except at high surface angles, where no attempt was made in the model to take into account the separation of the boundary-layer. Comparisons between the theory and experiments with the two other roughness types 


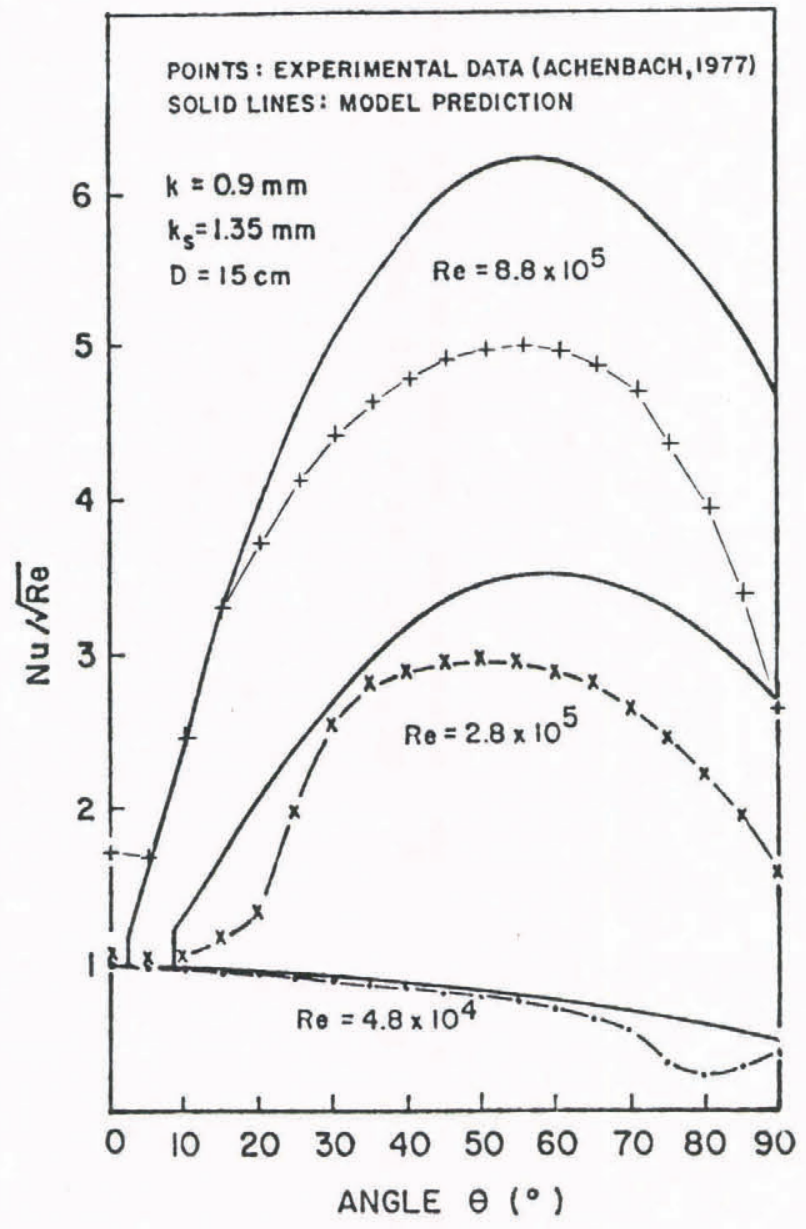

Fig.1. Local heat transfer coefficient $\mathrm{Nu} \sqrt{\mathrm{Re}}$ on a rough circular cylinder at various cylinder Reynolds numbers.

in Achenbach's (1977) experiments and with variable Reynolds number showed generally similar agreement as in Figure 1.

The emphasis in the present model is in estimating the overall heat transfer coefficient of the front half of a rough circular cylinder to be used in icing models intended to simulate the total icing rate of the object. The main interest here is, therefore, the dependence of the mean Nusselt number $\mathrm{Nu}_{\mathrm{m}}$ on the meteorological conditions, cylinder size and roughness. A feature of the theoretical

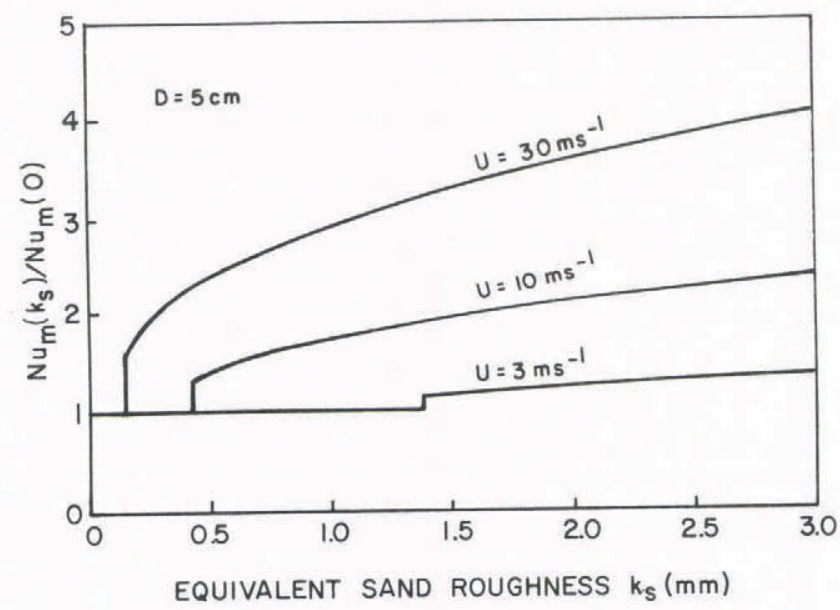

Fig.2. Ratio of the mean Nusselt number on a front half of a rough cylinder $\mathrm{Nu}_{m}\left(\mathrm{k}_{\mathrm{g}}\right)$ to its value $\mathrm{Nu}_{\mathrm{m}}(0)$ on a smooth cylinder as a function of the equivalent sand roughness $\mathrm{k}$. It is assumed in the model that the actual roughness element height $k=k_{s}$.

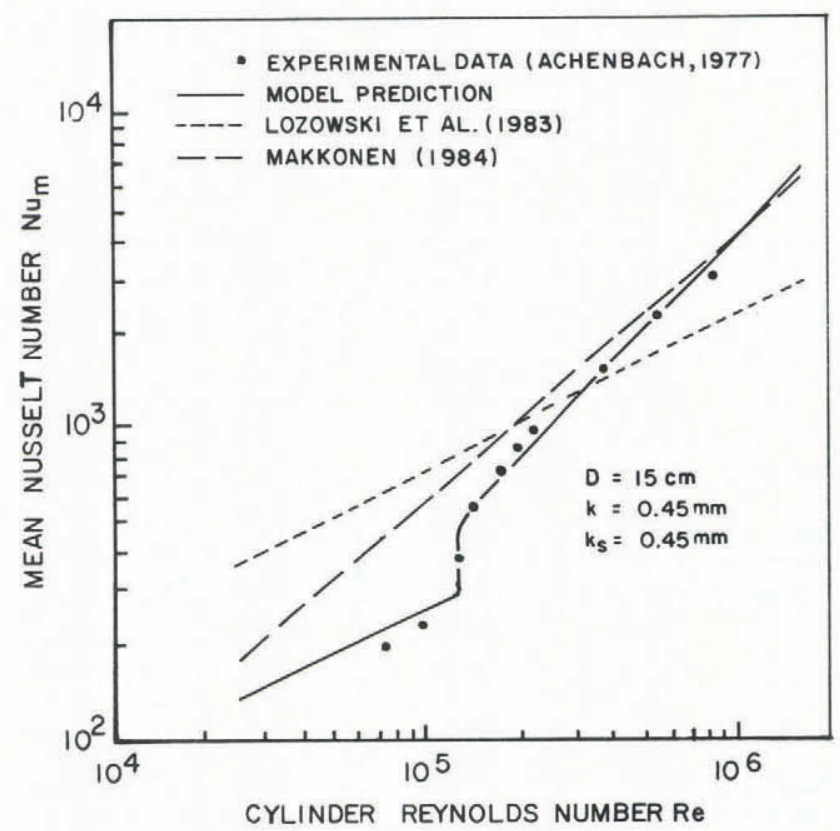

Fig.3. Mean Nusselt number $\mathrm{Nu}_{m}$ of the front half of a 15 $\mathrm{cm}$ diameter cylinder as a function of the cylinder Reynolds number.

model which deserves particular attention in this connection is that the cylinder Reynolds number $R e$ is not a similarity parameter as far as the mean heat transfer from the front half of the cylinder is concerned. For example, it turns out that the transition angle $\theta_{t r}$ is practically independent of the cylinder diameter $D$, but depends on the velocity $U$. It should be noted that owing to this non-similarity, the results in Figure 1 are valid for $\mathrm{D}=15 \mathrm{~cm}$ only.

Roughness affects the Nusselt number only when the boundary-layer flow is turbulent, and, therefore, the points in Figure 2 at which the mean Nusselt number $\mathrm{Nu}_{\mathrm{m}}\left(\mathrm{k}_{\mathrm{s}}\right)$ deviates from its value $\mathrm{Nu}_{\mathrm{m}}(0)$ for a smooth cylinder $\left(\mathrm{Nu}_{\mathrm{m}}(0)\right.$ is approximately equal to $\left.0.75 \times \sqrt{\mathrm{Re}}\right)$ indicate the critical roughness which causes transition on the cylinder surface. When $\mathrm{k}_{\mathrm{s}}$ increases and the transition occurs, there is first an abrupt increase in modelled $\mathrm{Nu}_{\mathrm{m}}$. With further increase in $k_{s}, \theta_{t r}$ decreases, with consequent increase in the mean Nusselt number. Simultaneously local Nusselt numbers in the turbulent region increase. Hence, there is first a

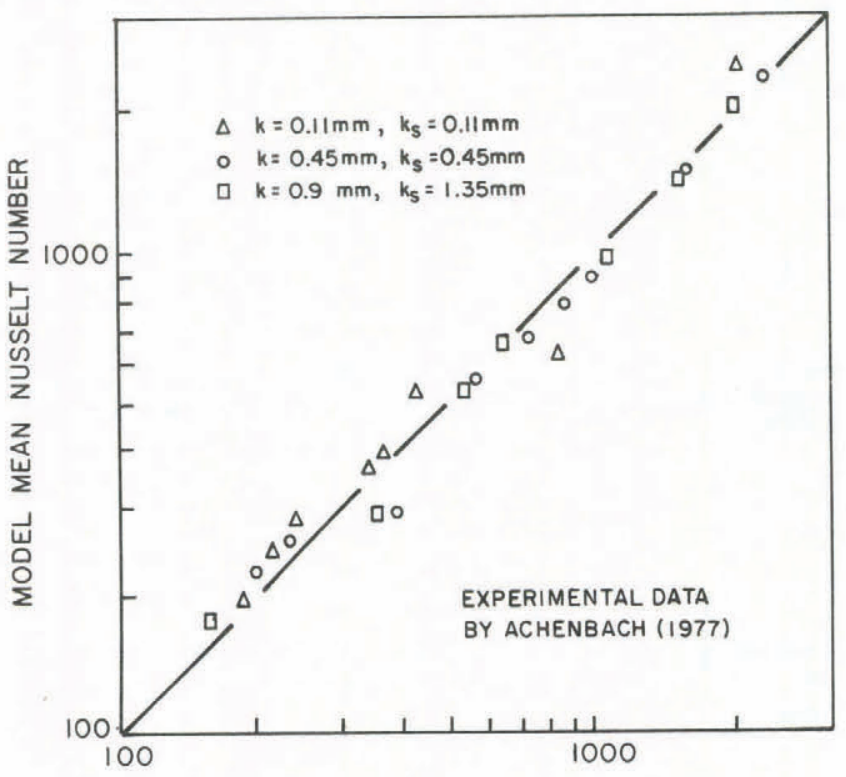

EXPERIMENTAL MEAN NUSSELT NUMBER

Fig.4. Mean Nusselt number of the front half of a $15 \mathrm{~cm}$ diameter cylinder calculated by the model vs the experimental value by Achenbach (1977). 
rapid increase in $\mathrm{Nu}_{\mathrm{m}}$ with increasing $\mathrm{k}_{\mathrm{s}}$, but as the transition angle approaches $0^{\circ}, \mathrm{Nu}_{\mathrm{m}}$ increases more slowly because there is no more noticeable increase in the proportion of the surface where the boundary-layer flow is turbulent. Figure 2 shows that the relative effect of roughness on the heat transfer coefficient increases with the free-stream velocity, so that the ratio $\mathrm{Nu}_{\mathrm{m}}(1 \mathrm{~mm}) / \mathrm{Nu}_{\mathrm{m}}(0)$ is about 2 in typical conditions of icing of stationary structures. It can also be seen in Figure 2 that $\mathrm{Nu}_{m}$ is not very sensitive to small variations in $\mathrm{k}_{\mathrm{s}}$, except close to the critical $\mathrm{k}_{\mathrm{g}}$ at which the transition occurs.

Figure 3 shows a comparison between the observed and calculated mean Nusselt numbers $\mathrm{Nu}_{m}$ for one roughness of Achenbach's (1977) measurements. In the figure two curves representing parametrizations of the heat transfer coefficient in two recent icing models are also shown. The small differences between the model predictions and the experimental values may be caused by neglecting the separation of the boundary-layer in the laminar case and by the fact that a part of the turbulent boundary-layer is not in the fully rough regime, for example. The model seems to be able to simulate the mean Nusselt number $\mathrm{Nu}_{m}$ well in the whole range of $\operatorname{Re}$ (at fixed $D$ ), and to describe the experimental data more precisely than the previous parametrizations used in the icing models.

The comparisons between the model results and the experimental data by Achenbach (1977) are summarized in Figure 4. The model results show significant deviations from the experimental values only at very high Reynolds numbers and at Reynolds numbers at which the error caused by inaccuracy in the transition angle has a great effect on $\mathrm{Nu}_{\mathrm{m}}$

Ice accretions formed in the wet growth conditions have typically roughness element heights of the order of 1-3 $\mathrm{mm}$, and at these roughnesses the model indicates that $\mathrm{Nu}_{m}$ is not very sensitive to $\mathrm{k}_{\mathrm{g}}$. This means that the formulation by Makkonen (1984) (Figure 4) in a wire icing model is probably a good estimate for $\mathrm{Nu}_{\mathrm{m}}$, at least at high

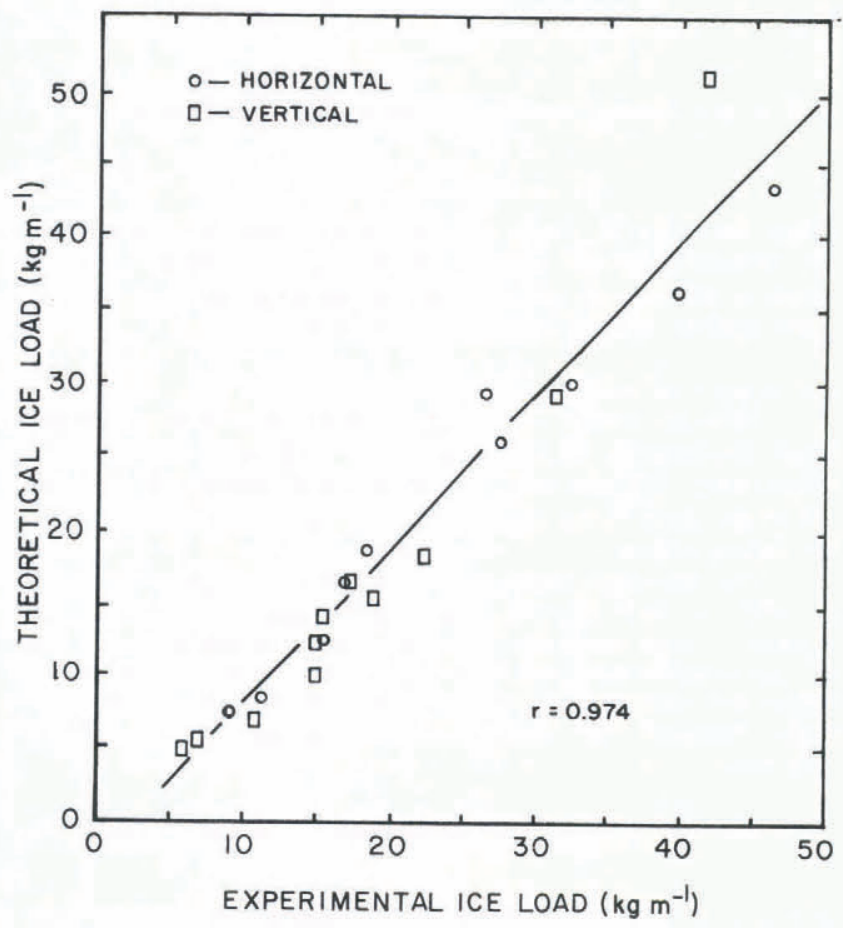

Fig.5. Ice mass on a fixed cylinder based on the theoretical model by Makkonen (1984) including the present heat transfer theory vs experimental ice mass by Stallabrass and Hearty (1967). The duration of icing is one hour, the liquid water content $3.2 \mathrm{gm}^{-3}$, the median volume droplet diameter $200 \mu \mathrm{m}$ and the wind speed $22.4 \mathrm{~ms}^{-1}$. Air temperature varies between $-16^{\circ} \mathrm{C}$ and $-4{ }^{\circ} \mathrm{C}$ and the cylinder diameter between $3.8 \mathrm{~cm}$ and $45.7 \mathrm{~cm}$. The estimated equivalent sand grain roughness of $2 \mathrm{~mm}$ is used in the model simulations. wind speeds, at which the major part of the boundary-layer is turbulent.

If the roughness element height of the ice accreted can be estimated, the use of the present heat transfer mode as part of an icing model results in good predictions of the icing rate. This is demonstrated in Figure 5 which shows a comparison between the experimental ice loads on fixed cylinders by Stallabrass and Hearty (1967) and the theory. The theoretical results in Figure 5 were obtained by modifying the time-dependent wire icing model by Makkonen (1984), so that the ice accreted is distributed on the front half of the cylinder only, and that the present heat transfer model is included. The regression line in Figure 5 is surprisingly close to direct proportionality, considering the uncertainty in the roughness element height and the deviations of the experimental ice deposits from the cylindrical shape.

The model proposed is also useful in the modeling of icing under dry growth conditions (rime formation), because the heat balance of the icing surface is needed in calculating the density of rime. The ice density, on the other hand, affects the rate of formation of ice loads on transmission line cables, as an example (Makkonen 1984).

The present model can readily be modified to describe heat transfer from non-cylindrical objects as well, by changing the pressure distribution to correspond to the shape in question. Doing this in practice requires more data on pressure distributions around objects of various shapes and rough surfaces.

\section{ACKNOWLEDGEMENTS}

This work was carried out while one of the authors (LM) was working under the Government of Canada Visiting Fellowship program instituted by the Natural Sciences and Engineering Research Council (NSERC).

\section{REFERENCES}

Achenbach E 1977 The effect of surface roughness on the heat transfer from a circular cylinder to the cross flow of air. International Journal of Heat Mass Transfer 20: $359-369$

Güven O, Farell C, Patel V C 1980 Surface roughness effects on the mean flow past circular cylinders. Journal of Fluid Mechanics 98: 673-701

Kays W M, Crawford M E 1980 Convective heat and mass transfer. New York, McGraw-Hill

Lozowski E P, Stallabrass J R, Hearty P F 1983 The icing of an unheated, non-rotating cylinder. Part I: A simulation model. Journal of Climate and Applied Meteorology 22: 2063-2074

Makkonen L 1984 Modeling of ice accretion on wires. Journal of Climate and Applied Meteorology 23: 929-939

Makkonen L 1985 Heat transfer and icing of a rough cylinder. Cold Regions Science and Technology 10: 105-116

Nakamura Y, Tomonari Y 1982 The effects of surface roughness on the flow past circular cylinders at high Reynolds numbers. Journal of Fluid Mechanics 123: 363-378

Owen P R, Thomson W R 1963 Heat transfer across rough surfaces. Journal of Fluid Mechanics 15: 321-334

Stallabrass J R, Hearty P F 1967 The icing of cylinders in conditions of simulated freezing sea spray. Mechnical Engineering Report MD-50, National Research Council of Canada.

White
McGraw-Hill 